\title{
The Role of Vitamin D3 Therapy in Pediatric Bronchiectasis Severity (CF versus Non-CF Patients)
}

\author{
Heba A. Ali ${ }^{*}$, Thrwat E. Deraz' ${ }^{1}$ Dina A. Mohamed ${ }^{2}$, Menna Z. Mahmoud ${ }^{3}$ \\ ${ }^{1}$ Department of Pediatrics, Pulmonolgy Division, Ain Shams University Children's Hospital, Faculty of Medicine, Cairo, Egypt \\ ${ }^{2}$ Department of Clinical Pathology, Ain Shams University Hospital, Faculty of Medicine, Cairo, Egypt \\ ${ }^{3}$ Ministry of Health, Faculty of Medicine, Cairo, Egypt \\ Email:`heba_omara@hotmail.com, tharwat_deraz@hotmail.com,Dina_Aly@hotmail.com,moonessawy@gmail.com
}

How to cite this paper: Ali, H.A., Deraz, T.E., Mohamed, D.A. and Mahmoud, M.Z. (2020) The Role of Vitamin D3 Therapy in Pediatric Bronchiectasis Severity (CF versus Non-CF Patients). Open Journal of Pediatrics, 10, 521-534.

https://doi.org/10.4236/ojped.2020.103053

Received: June 15, 2020

Accepted: September 22, 2020

Published: September 25, 2020

Copyright ( 2020 by author(s) and Scientific Research Publishing Inc. This work is licensed under the Creative Commons Attribution International License (CC BY 4.0).

http://creativecommons.org/licenses/by/4.0/

(c) (i) Open Access

\begin{abstract}
Objective: To determine and compare the effect of vitamin D3 supplementation on modifying the disease severity in cystic fibrosis (CF) and non-CF bronchiectasis pediatric patients. Methods: A randomized clinical trial evaluating the role of oral vitamin D3 supplementation for six months, was performed in forty patients with CF and non-CF bronchiectasis under the age of 18 years with vitamin $\mathrm{D}$ deficiency or insufficiency. The primary outcome was to reach the sufficient Vitamin D level, the secondary outcome was to reevaluate bronchiectasis severity by following up the frequency, severity of pulmonary exacerbations and lung function after vitamin D3 supplementation. Results: Forty patients completed the trial. The percentage of improvement of vitamin D level after vitamin D3 supplementation for six months was significantly higher in CF $(88.3 \%)$ than non-CF bronchiectasis patients (59.82\%) $(\mathrm{P}=0.03)$. Additionally, moderate to severe pulmonary exacerbations significantly decreased by more than $60 \%, 45 \%(P=0.001,0.005)$ and frequent exacerbations decreased by $15 \%, 10 \%(\mathrm{P}=0.327,0.490)$, while the forced expiratory volume in 1 (FEV1) significantly increased by $17 \%$ and $15 \%$ in non CF bronchiectasis and CF patients respectively ( $\mathrm{p}<0.001$ ). Conclusions: Vitamin D3 therapy was effective in decreasing the frequency and severity of pulmonary exacerbations and preserving lung function. Thereby, improving the disease severity even more in non-CF bronchiectasis than $\mathrm{CF}$ patients.
\end{abstract}

\section{Keywords}

Cystic Fibrosis, Non-CF Bronchiectasis, Vitamin D3 Supplementation, Exacerbation, FEV1 


\section{Introduction}

Bronchiectasis is a chronic inflammatory respiratory disorder characterized by bronchial dilatation, and symptoms of productive cough, dyspnea and repeated respiratory infections requiring multiple courses of antibiotics [1]. Nowadays, bronchiectasis is classified as either related or unrelated to cystic fibrosis (CF), with the latter defined as non-CF bronchiectasis [2].

Vitamin D deficiency occurs commonly in patients with CF [3] \& non-CF bronchiectasis. In these patients, vitamin $\mathrm{D}$ deficiency can be caused by multiple factors including pancreatic exocrine insufficiency, lack of sunlight exposure and decreased vitamin D-binding protein [3]. In addition, reduced outdoor physical activity which is a common consequence of chronic lung diseases, can lead to reduced exposure to sunlight and therefore vitamin-D deficiency [4].

Vitamin D down-regulates cytokines and chemokines that promote tissue destruction, that are found in abundance in $\mathrm{CF}$ and non-CF bronchiectatic lungs [5] [6]. It was shown that CF respiratory epithelial cells and macrophages incubated with $1.25(\mathrm{OH}) 2 \mathrm{D}$ showed a significant down-regulation in the neutrophil attracting chemokine, IL-8 [7],

The anti-inflammatory activity of vitamin D may originate from the enhancement of anti-inflammatory/regulatory cytokines secretion, such as IL-10 [8]. Vitamin D, as it was aforementioned, may have anti-infective and anti-inflammatory properties and therefore may play some role in the pathogenesis of bronchiectasis [9].

Vitamin D may preserve lung function depending on several studies in cystic fibrosis and other chronic lung diseases which include improved airway remodeling, decreased airway inflammation, and decreased airway bacterial colonization [10]. In addition, vitamin D therapy may increase anti-microbial peptide production and decrease pro-inflammatory cytokines which could result in improved clinical outcomes [11].

\section{Subjects and Methods}

\subsection{Study Design}

This was a randomized clinical trial. The study was registered at https://www.clinicaltrials.gov/ prior to inclusion of the patients in the study (NCT04411901), comparing the role of vitamin D3 therapy in pediatric patients with $\mathrm{CF}$ and non-CF bronchiectasis who were vitamin D deficient or insufficient. The patients' groups received maximum therapeutic dose of cholecalciferol (D3) orally daily for complete six months. All CF patients continued receiving their ordinary multivitamins supplementation unchanged apart from vitamin D. The study was open-label and consisted of six months of supplementation followed by two months of washout. The trial has been conducted at the children's Hospital, Ain Shams University hospitals located in Cairo (Egypt) during the interval from July 2018 to February 2019. 
The study was approved by the Research Ehical committee, faculty of medicine, Ain Shams University. All patients were welcomed to share in the study and informed consents were obtained from the parents and the patients older than 8 years before the inclusion within the study. A summary of the overall study design is presented in (Figure 1).

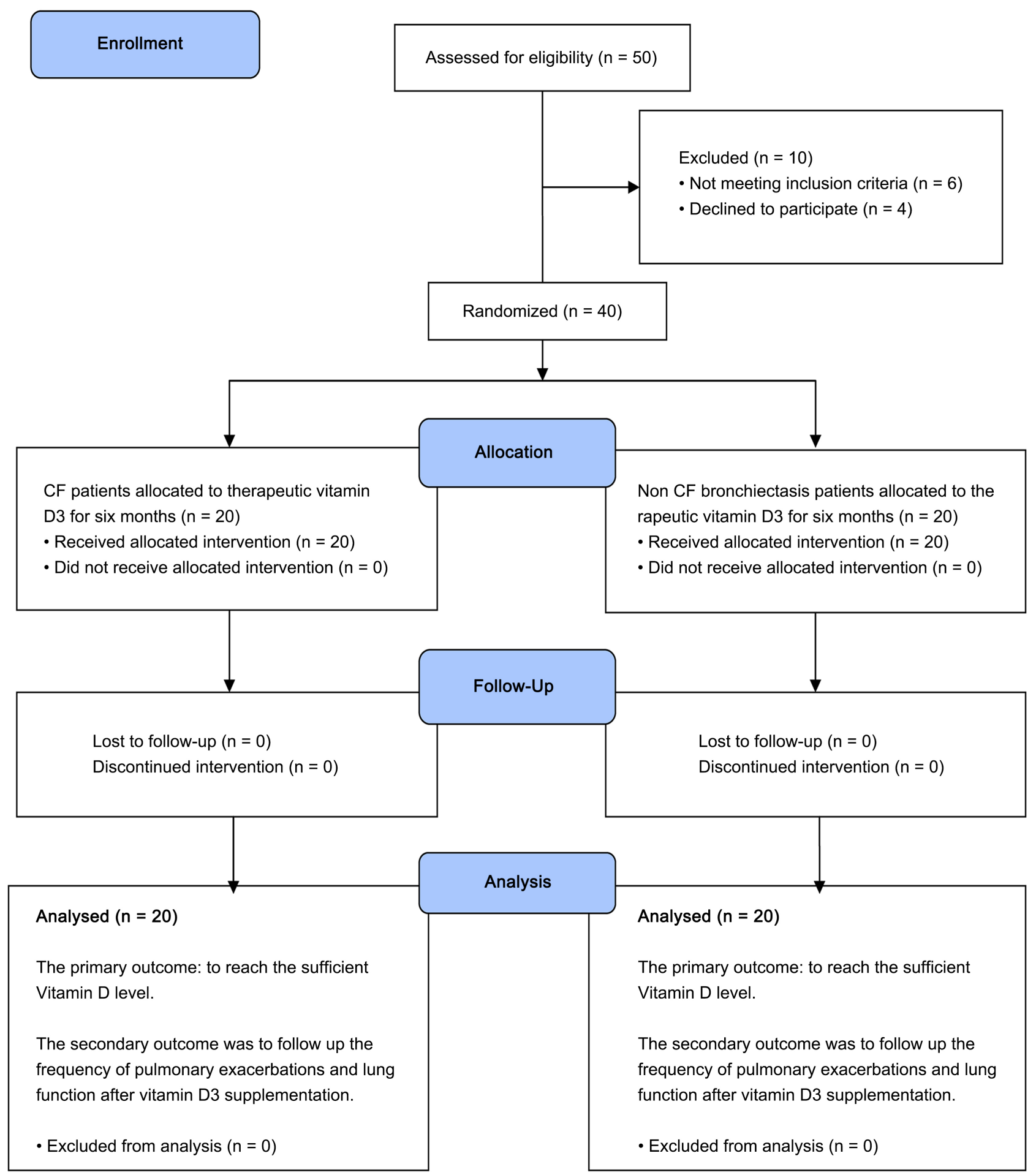

Figure 1. CONSORT diagram showing the flow of patients through each stage of the study. 


\subsection{Patient Selection}

Fifty patients were screened and forty patients \{Twenty non CF bronchiectasis patients (group A) and twenty CF patients (group B)\} who were following in Chest Clinic at Children's Hospital were enrolled in the study. Eligibility criteria included 1) ages less than 18 years, 2) Patients with documented diagnosis of CF (by the presence of a twice positive sweat chloride test and or paired known $\mathrm{CF}$ genetic mutations) [12], 3) Patients with non-CF bronchiectasis diagnosed clinically and radiologically with a clinical history consistent with bronchiectasis, high resolution computerized tomography (HRCT) of the lungs-confirmed diagnosis and negative sweat chloride test. The clinical suspicion of bronchietasis in children is performed according to the Thoracic Society of Australia and New Zealand guidelines, the prerequisites for diagnosis include: 1) persistent wet cough not responding to four weeks of antibiotics; 2) more than three episodes of wet cough per year responding to antibiotics and lasting more than four weeks; or 3) a persisting for more than six weeks chest radiograph abnormality despite the appropriate treatment [13], 4) Vitamin D deficient or insufficient CF and non-CF bronchiectasis patients. The patients are excluded if that they had 1) sufficient Vitamin D level, 2) chronic lung diseases aside from CF and non-CF bronchiectasis, 3) liver or renal diseases or 4) reported taking vitamin-D supplements or steroid therapy within the last 6 weeks.

\subsection{Measurements}

After consent was obtained, detailed history and baseline data about the patients were collected. Additionally, a therapeutic history including any vitamin D supplements was obtained. Clinical data including sex, age, height, weight, body mass index, pulmonary function testing results using standardized spirometry (just for cooperative patients older than six years) and radiological investigations (chest X-ray, HRCT using Bhalla score) at the baseline and throughout the pulmonary exacerbations were obtained. Basal serum vitamin D level was also recorded.

Lung function was measured by forced expiratory volume in $1 \mathrm{~s}$ (FEV1), forced vital capacity (FVC) and FEV1/FVC. FVC and FEV1 measurements were reported as percent of predicted values. All pulmonary function tests were performed and interpreted consistent with the American Thoracic Society (ATS)/ European Respiratory Society (ERS) standards [14] [15].

Frequency and severity of pulmonary exacerbations were recorded at the first visit using the medical records and self recording of the patients with a special stress on the frequency, severity, duration and antibiotics taken during each exacerbation within the previous 12 months. A pulmonary exacerbation was defined as a deterioration of three or more of the followings, Cough, Sputum volume/consistency, breathlessness/exercise intolerance, fatigue/malaise and hemoptysisas recommended by modified Fuchs criteria and BTS bronchiectasis guidelines [16] [17]. 
A mild-to-moderate exacerbation was further defined as: 1 to 2 signs or symptoms present or that the symptom severity is mild. Severe exacerbations were defined as emergency department visits for exacerbations, need for ICU admission, acute respiratory failure, exacerbated chronic respiratory failure or significant decline of So2 or respiratory functions [17] [18].

Frequent exacerbations were defined as more than 3 exacerbations per annum [19].

\subsection{Description of Study Procedures}

Twenty CF and twenty non-CF bronchiectasis patients with vitamin D deficiency or insufficiency were assigned to receive the utmost therapeutic dose of vitamin D3 (cholecalciferol). The vitamin D3 therapy included oral daily doses which were consistent with age (2000 IU for infants up to 1 year, 4000 IU for children aged 1 - 10 years, and 10,000 IU for those aged from 10 - 17 years) [20]. Additionally, $60 \mathrm{mg}$ per $\mathrm{kg}$ of calcium supplement was administrated to decrease the risk of hypocalcemia for all patients and pancreatic enzyme replacement therapy (PERT) was given for the CF patients for a complete six months.

An assay of Serum Vitamin D 25(OH)D was done 4 weeks after the completion of six months of vitamin D3 and calcium treatment. Then the Patients were observed for the upcoming pulmonary exacerbations and lung function post vitamin D3 supplementation.

\subsection{Assay of Serum Vitamin D}

Three $\mathrm{ml}$ of venous blood were collected from each patient under aseptic conditions. Serum was separated and vitamin D was measured spectrophotometrically at a wavelength of $450 \mathrm{~nm}$ using Human25_dihydroxy vitamin D (25-OH-D) ELISA Kit [21]. Vitamin D sufficiency was defined as $25(\mathrm{OH}) \mathrm{D} \geq 30 \mathrm{ng} / \mathrm{mL}$, Vitamin D insufficiency as 25(OH)D between 21 and $29 \mathrm{ng} / \mathrm{mL}$ and Vitamin D deficiency as $25(\mathrm{OH}) \mathrm{D} \leq 20 \mathrm{ng} / \mathrm{ml}[22]$.

\subsection{Statistical Analysis}

Data were analyzed statistically in terms of mean \pm standard deviation $( \pm S D)$, and range, or frequencies and percentages and $P$-values less than 0.05 was considered statistically significant while $P$ less than 0.01 was considered highly significant. All statistical calculations were done using computer programs SPSS (Statistical Package for the Social Science; SPSS Inc., Chicago, IL, USA) version 15 for Microsoft Windows. With a total of forty patients (Twenty CF patients and twenty non-CF bronchiectasis patients), there is $80 \%$ power to compare the effect of vitamin D3 therapy on bronchiectasis severity between both groups of patients using 0.05 significance level.

\section{Results}

The forty studied patients received vitamin D3 for six months followed by two 
months wash-out. No significant adverse effects were recorded. Baseline characteristics and statistical analysis were done for the 40 patients who completed the study visits and had follow-up laboratory and clinical assessments.

The basic demographic, anthropometric and radiological data of the studied patients are presented in Table 1 . Where, there was a statistically significant difference between CF patients (group B) and non CF bronchiectasis patients (group A) as regard mean age, weight $\&$ height which were lower among $\mathrm{CF}$ patients than non-CF bronchiectasis patients $(p=0.016,0.016,0.007)$ respectively.

Table 1. Comparison between non-CF bronchiectasis patients and CF patients according to demographic, anthropometric and radiological data.

\begin{tabular}{|c|c|c|c|c|c|}
\hline \multirow{2}{*}{\multicolumn{2}{|c|}{$\begin{array}{l}\text { Demographic and } \\
\text { anthropometric data }\end{array}$}} & \multirow{2}{*}{$\begin{array}{l}\text { Group A } \\
\text { No. }=20\end{array}$} & \multirow{2}{*}{$\begin{array}{l}\text { Group B } \\
\text { No. }=20\end{array}$} & \multirow{2}{*}{ Test value } & \multirow{2}{*}{$\mathrm{P}$-value } \\
\hline & & & & & \\
\hline \multirow{3}{*}{ Sex } & Male & $11(55.0 \%)$ & $15(75.0 \%)$ & \multirow{3}{*}{3.840} & \multirow{3}{*}{0.147} \\
\hline & & & & & \\
\hline & Female & $9(45.0 \%)$ & $5(25.0 \%)$ & & \\
\hline \multirow{3}{*}{ Age (years) } & Mean \pm SD & $9.35 \pm 4.49$ & $5.35 \pm 4.02$ & \multirow{3}{*}{4.440} & \multirow{3}{*}{0.016} \\
\hline & & & & & \\
\hline & Range & $3-17$ & $1-15$ & & \\
\hline \multirow{3}{*}{ Weight (kgs) } & Mean \pm SD & $27.12 \pm 14.48$ & $16.48 \pm 8.20$ & \multirow{3}{*}{8.322} & \multirow{3}{*}{0.016} \\
\hline & & & & & \\
\hline & Range & $9.3-56$ & $8.5-38$ & & \\
\hline \multirow{3}{*}{ Weight $\mathrm{Z}$ score } & Mean \pm SD & $0.05 \pm 0.82$ & $-0.48 \pm 0.70$ & \multirow{3}{*}{4.619} & \multirow{3}{*}{0.014} \\
\hline & & & & & \\
\hline & Range & $-1.11-1.52$ & $-1.15-1.35$ & & \\
\hline \multirow{3}{*}{ Height $(\mathrm{cm})$} & Mean \pm SD & $124.20 \pm 26.42$ & $98.05 \pm 26.57$ & \multirow{3}{*}{9.856} & \multirow{3}{*}{0.007} \\
\hline & & & & & \\
\hline & Range & $88-160$ & $65-144$ & & \\
\hline \multirow{3}{*}{ Height $Z$ score } & Mean \pm SD & $0.19 \pm 0.86$ & $-0.57 \pm 0.96$ & \multirow{3}{*}{5.795} & \multirow{3}{*}{0.005} \\
\hline & & & & & \\
\hline & Range & $-1.4-1.46$ & $-1.76-1.09$ & & \\
\hline \multirow{3}{*}{ BMI } & Mean \pm SD & $16.25 \pm 2.96$ & $16.11 \pm 1.32$ & \multirow{3}{*}{1.603} & \multirow{3}{*}{0.449} \\
\hline & & & & & \\
\hline & Range & $12.48-24.89$ & $12.35-22$ & & \\
\hline \multirow{3}{*}{ BMI Z score } & Mean \pm SD & $-0.29 \pm 0.62$ & $-0.04 \pm 1.07$ & \multirow{3}{*}{1.490} & \multirow{3}{*}{0.234} \\
\hline & & & & & \\
\hline & Range & $-1.61-0.62$ & $-1.67-1.15$ & & \\
\hline \multirow{3}{*}{ Bhalla scoring } & Mild (\%) & $10(50.0 \%)$ & $12(60.0 \%)$ & \multirow{3}{*}{1.182} & \multirow{3}{*}{0.553} \\
\hline & Moderate (\%) & $7(35.0 \%)$ & $7(35.0 \%)$ & & \\
\hline & Severe (\%) & $3(15.0 \%)$ & $1(5.0 \%)$ & & \\
\hline
\end{tabular}

Group A: Non-CF bronchiectasis patients; Group B: CF bronchiectasis patients. 
Vitamin D level in CF and non-CF bronchiectasis after vitamin D3 supplementation:

There was a highly statistically significant improvement in both groups as regard the vitamin D level after supplementation (P-value $<0.001$ ) (as shown in Table 2). In addition, the percentage of improvement of vitamin $D$ level was significantly higher in group B (CF patients) (88.3\%) than in group A (non-CF patients) $(59.82 \%)$ after vitamin D3 supplementation for six months $(\mathrm{P}$-value $=$ 0.030) (Figure 2).

Table 2. Serum vitamin D level after Vitamin D3 supplementation in both CF and non-CF bronchiectasis groups.

\begin{tabular}{|c|c|c|c|c|c|}
\hline & & Group A & Group B & \multirow{2}{*}{ Test value• } & \multirow{2}{*}{$\mathrm{P}$-value } \\
\hline & & No. $=20$ & No. $=20$ & & \\
\hline \multirow{2}{*}{$\begin{array}{l}\text { Vitamin D level before } \\
\text { supplementation }\end{array}$} & Mean \pm SD & $22.72 \pm 7.20$ & $21.22 \pm 6.80$ & \multirow{2}{*}{11.05} & \multirow{2}{*}{$<0.001$} \\
\hline & Range & $11-29$ & $10-29$ & & \\
\hline \multirow{2}{*}{$\begin{array}{l}\text { Vitamin D level after } \\
\text { supplementation }\end{array}$} & Mean \pm SD & $33.40 \pm 7.92$ & $36.30 \pm 11.09$ & \multirow{2}{*}{0.397} & \multirow{2}{*}{0.674} \\
\hline & Range & $25-55$ & $23-69$ & & \\
\hline Paired t-test & $\mathrm{P}$-value & $<0.001$ & $<0.001$ & & \\
\hline \multirow[t]{2}{*}{$\%$ of improvement } & Median (IQR) & $\begin{array}{c}\mathbf{5 9 . 8 2} \\
(33.3-82.57)\end{array}$ & $\begin{array}{c}\mathbf{8 8 . 3} \\
(72.8-113.94)\end{array}$ & \multirow[t]{2}{*}{$2.164 \neq$} & \multirow[t]{2}{*}{0.030} \\
\hline & Range & $10-160$ & $4.55-200$ & & \\
\hline
\end{tabular}

$\because$ One Way ANOVA test; $\neq$ Mann-Whitney test; Group A: non-CF bronchiectasis patients; Group B: CF bronchiectasis patients.

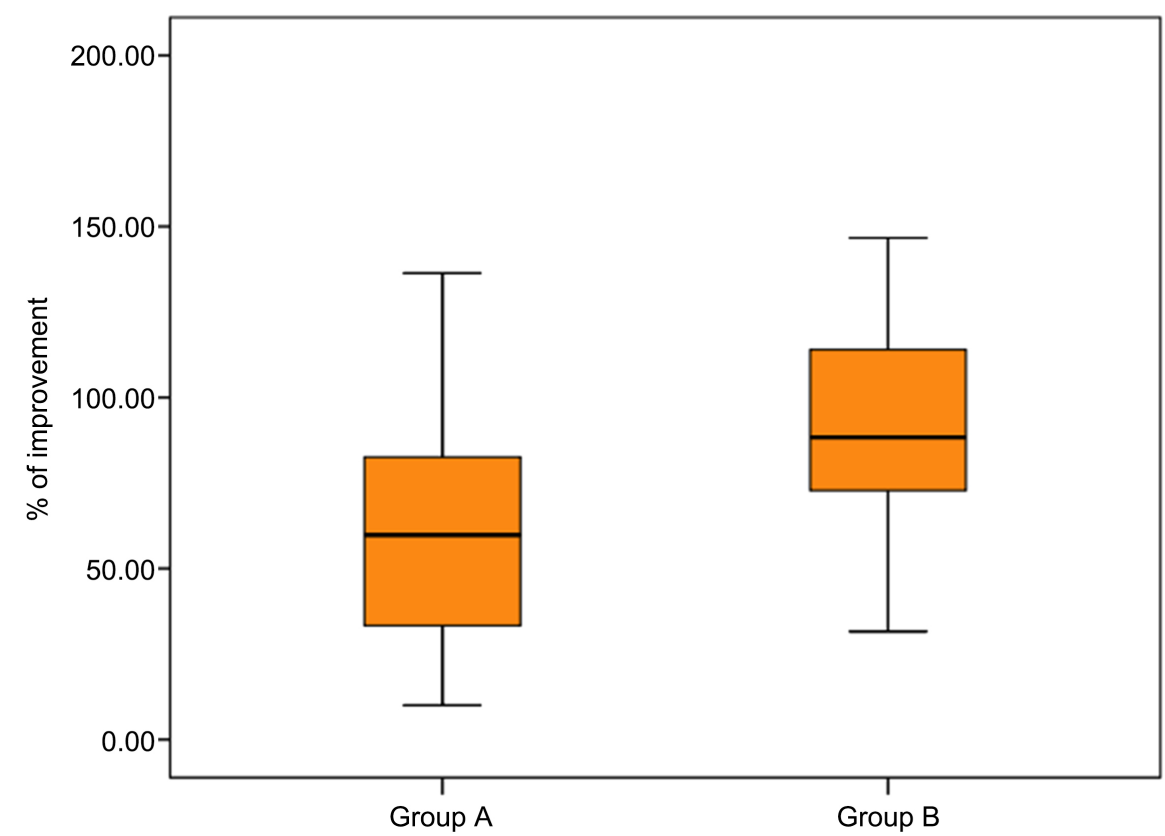

Figure 2. Shows a higher percentage of improvement in serum vitamin D in CF than in non-CF bronchiectasis patients after vitamin D3 supplementation. 
Pulmonary exacerbations and vitamin D supplementation:

As presented in (Table 3 \& Table 4), there was a highly statistically significant difference in the severity of pulmonary exacerbations in both non CF bronchiectasis and CF groups after vitamin D3 supplementation $(P=0.001,0.005)$ respectively where moderate to severe exacerbations significantly decreased in non-CF bronchiectasis patients (60\%) which was higher than among CF patients $(45 \%)$.

Table 3. The effect of vitamin D3 supplementation on the severity of pulmonary exacerbations in CF \& non-CF bronchiectasis groups.

\begin{tabular}{|c|c|c|c|c|c|c|c|}
\hline \multirow{2}{*}{\multicolumn{2}{|c|}{ Exacerbations severity }} & \multicolumn{2}{|c|}{ Group A } & \multicolumn{2}{|c|}{ Group B } & \multirow{2}{*}{ Test value ${ }^{\star}$} & \multirow{2}{*}{ P-value } \\
\hline & & No. & $\%$ & No. & $\%$ & & \\
\hline \multirow{4}{*}{$\begin{array}{l}\text { Before vitamin D } \\
\text { supplementation }\end{array}$} & Absent & 0 & $0.0 \%$ & 0 & $0.0 \%$ & \multirow{4}{*}{2.613} & \multirow{4}{*}{0.271} \\
\hline & Mild & 3 & $15.0 \%$ & 4 & $20.0 \%$ & & \\
\hline & Moderate & 11 & $55.0 \%$ & 6 & $30.0 \%$ & & \\
\hline & Severe & 6 & $30.0 \%$ & 10 & $50.0 \%$ & & \\
\hline \multirow{4}{*}{$\begin{array}{l}\text { After vitamin D } \\
\text { supplementation }\end{array}$} & Absent & 2 & $10.0 \%$ & 3 & $15.0 \%$ & \multirow{4}{*}{1.682} & \multirow{4}{*}{0.641} \\
\hline & Mild & 13 & $65.0 \%$ & 10 & $50.0 \%$ & & \\
\hline & Moderate & 5 & $25.0 \%$ & 6 & $30.0 \%$ & & \\
\hline & Severe & 0 & $0.0 \%$ & 1 & $5.0 \%$ & & \\
\hline \multicolumn{2}{|c|}{ Test value } & \multicolumn{2}{|c|}{16.500} & \multicolumn{2}{|c|}{12.935} & & \\
\hline \multicolumn{2}{|c|}{$\mathrm{P}$-value } & \multicolumn{2}{|c|}{0.001} & \multicolumn{2}{|c|}{0.005} & & \\
\hline
\end{tabular}

*: Chi-square test.

Table 4. The frequency of pulmonary exacerbations in both groups before \& after vitamin D3 supplementation.

\begin{tabular}{|c|c|c|c|c|}
\hline \multirow{2}{*}{ Frequency of exacerbations } & Group A & Group B & \multirow{2}{*}{ Test value ${ }^{\star}$} & \multirow{2}{*}{ P-value } \\
\hline & No. $=20$ & No. $=20$ & & \\
\hline \multicolumn{5}{|l|}{ Before supplementation } \\
\hline Less than 3 times & $11(55.0 \%)$ & $13(65.0 \%)$ & \multirow[b]{2}{*}{0.417} & \multirow[b]{2}{*}{0.518} \\
\hline More than 3 times & $9(45.0 \%)$ & $7(35.0 \%)$ & & \\
\hline \multicolumn{5}{|l|}{ After supplementation } \\
\hline Less than 3 times & $14(70 \%)$ & $15(75 \%)$ & \multirow{2}{*}{0.125} & \multirow{2}{*}{0.724} \\
\hline More than 3 times & $6(30 \%)$ & $5(25 \%)$ & & \\
\hline Test Value & 0.960 & 0.476 & & \\
\hline P-Value & 0.327 & 0.490 & & \\
\hline
\end{tabular}

*: Chi-square test. 
In addition, frequent pulmonary exacerbations in non-CF bronchiectasis and CF patients decreased after vitamin D3 supplementation by $15 \%, 10 \%$ respectively, although the difference was statistically non-significant $(P=0.327,0.490)$.

Lung functions and vitamin D supplementation:

As shown in (Table 5), There was a highly statistically significant improvement in FEV1 in both groups after vitamin D3 supplementation where the degree of improvement in FEV1) after vitamin D supplementation was 17\%, 15\% in non-CF bronchiectasis and cystic fibrosis respectively ( $\mathrm{P}$-value $<0.001$ ).

\section{Discussion}

To our knowledge, this is the first study to determine and compare the effectiveness of Vitamin D3 therapy in CF versus non-CF bronchiectasis pediatric patients who were vitamin D deficient or insufficient. The primary endpoint was to reach the therapeutic vitamin D level, secondary endpoints investigated the effect of vitamin D3 therapy on the frequency and severity of pulmonary exacerbations as well as lung function.

Cholecalciferol (vitamin D3) was chosen in our study because cholecalciferol was superior to ergocalciferol (vitamin D2) in raising serum 25(OH)D concentrations with optimal absorption and sustained improvement as reported by previous studies [20].

The current study showed that the mean age, weight and height were significantly lower among CF patients than among non-CF bronchiectasis patients (Table 1) which may be due to earlier median age of diagnosis of CF patients which is 6 - 8 months; as two thirds of CF patients are diagnosed by 1 year of age. While only one fifth of pediatric non-CF bronchiectasis cases are diagnosed in the first year of life.

Table 5. Comparison between groups A \& B as regard FEV1 results before and after vitamin D3 supplementation.

\begin{tabular}{|c|c|c|c|c|c|}
\hline \multicolumn{2}{|l|}{ FEV1 } & Group A & Group B & \multirow{2}{*}{ Test value } & \multirow{2}{*}{ P-value } \\
\hline & & No. $=15$ & No. $=10$ & & \\
\hline \multirow{2}{*}{ Before supplementation } & & $69.54 \pm 9.53$ & $75.38 \pm 10.20$ & \multirow{2}{*}{$-1.436 \bullet$} & \multirow{2}{*}{0.163} \\
\hline & Range & $40-82$ & $65-96$ & & \\
\hline \multirow[b]{2}{*}{ After supplementation } & Mean \pm SD & $80.85 \pm 8.79$ & $85.25 \pm 7.27$ & \multirow[b]{2}{*}{$-1.252 \bullet$} & \multirow[b]{2}{*}{0.222} \\
\hline & Range & $63-102$ & $78-100$ & & \\
\hline Paired t-test & & -7.603 & -6.509 & & \\
\hline $\mathrm{P}$-value & & $<0.001$ & $<0.001$ & & \\
\hline \multirow[t]{2}{*}{$\%$ change } & Median (IQR) & $\begin{array}{c}16.75 \\
(6.83-23.13)\end{array}$ & $\begin{array}{c}15.16 \\
(7.56-18.96)\end{array}$ & \multirow[t]{2}{*}{$-0.636 \neq$} & \multirow[t]{2}{*}{0.525} \\
\hline & Range & $4-57.5$ & $4.17-22.86$ & & \\
\hline
\end{tabular}

•: Independent t-test; $¥:$ Mann-Whitney test. 
Our study has identified a significant relation between vitamin-D3 supplementation and the improvement of bronchiectasis severity, unexpectedly, more in non-CF bronchiectasis than in CF patients.

The current study found that the overall mean increase in $25(\mathrm{OH}) \mathrm{D}$ was $(16.15,11.75) \mathrm{ng} / \mathrm{mL}$ and $15 / 20(75 \%), 11 / 20(55 \%)$, achieved a $25(\mathrm{OH}) \mathrm{D}$ concentration $\geq 30 \mathrm{ng} / \mathrm{mL}$ in both $\mathrm{CF}$ and non-CF bronchiectasis patients respectively (data not shown in the results). Therefore, the percentage of improvement of vitamin D level after vitamin D supplementation for six months was significantly higher in CF (88.3\%) than non-CF bronchetasis patients (59.82\%) (Table 2) which may be due to more adherence of the CF patients to treatment than the non-CF bronchiectasis patients.

Our results go parallel with a recent study conducted by Bartely et al. [23] on " 32 adults with non-CF bronchiectasis received an initial $2.5 \mathrm{mg}$ (100,000 IU) vitamin D3 oral loading dose and $0.625 \mathrm{mg}(25,000 \mathrm{IU})$ vitamin D3 weekly for 24 weeks, reported that the initial, average $25(\mathrm{OH}) \mathrm{D}$ level was $71 \mathrm{nmol} / \mathrm{L}(28.4$ $\mathrm{ng} / \mathrm{ml}$ ) and Vitamin D3 supplementation significantly increased serum $25(\mathrm{OH}) \mathrm{D}$ levels $(\mathrm{p}<0.001)$ in patients with non-CF bronchetasis, rising to 218 $\mathrm{nmol} / \mathrm{L}(87.2 \mathrm{ng} / \mathrm{ml})$ at 3 months and $205 \mathrm{nmol} / \mathrm{L}(82 \mathrm{ng} / \mathrm{ml})$ at 6 months after vitamin D3 supplementation".

On the same hand, Simoneau et al. [24] in "a randomized controlled trial comparing 50,000 IU of ergocalciferol (vitamin D2) twice weekly for 8 weeks versus 50,000 IU of cholecalciferol (vitamin D3) weekly in 47 patients with CF, with pancreatic insufficiency, aged 6 - 21 years, reported that overall, 69\% of pediatric CF patients with vitamin $\mathrm{D}$ insufficiency who received high dose of vitamin D2 for 12 weeks showed a significant increase in the $25(\mathrm{OH}) \mathrm{D}$ concentration and achieved the goal $25(\mathrm{OH}) \mathrm{D}$ concentration of greater than $30 \mathrm{ng} / \mathrm{mL}$ versus $62 \%$ in those who received vitamin D3 ( $\mathrm{p}=0.65)$ ".

Also, our study has demonstrated a link between vitamin D3 supplementation, severity and frequency of pulmonary exacerbations where moderate to severe exacerbations significantly decreased by $(60 \%, 45 \%)$ in non-CF and CF patients respectively $(\mathrm{P}=0.001,0.005)$. Moreover, the frequent ones decreased by $15 \%$ and $10 \%$ in non-CF and CF patients $(\mathrm{P}=0.327,0.490)$ (Table 3$)$.

Our findings were supported by McCauley et al. [3] who reported that having a higher serum 25-hydroxyvitamin D in children was protective of having a pulmonary exacerbation. Similarly, several previous studies [9] [25] reported that the high dose vitamin D3 therapy in CF patients rapidly improved vitamin $\mathrm{D}$ status and was associated with improved re-hospitalization rates by pulmonary exacerbations and lung function.

On the contrary, Bartely et al. [23] found no significant association between supplemented $25(\mathrm{OH}) \mathrm{D}$ levels and frequency or severity of exacerbations. His explanation was that the study was not powered to detect effects on exacerbation frequency.

In Both $\mathrm{CF}$ and non-CF bronchiectasis, vitamin $\mathrm{D}$ concentrations have been 
associated with lung function [10]. "The mechanisms by which vitamin D may confer beneficial effects on lung function are unclear, but may be through induction of anti-microbial peptides such as human cathelicidin (LL-37) and beta-defensins, improved anti-oxidant status, improved lung remodeling and decreased airway bacterial colonization" [9].

The current study assessed the change in, FEV1 (percent predicted) (Table 5), FVC\% of predicted and FEV1/FVC before and after vitamin D3 supplementation and it was found that there was a highly statistically significant improvement in lung functions after vitamin D3 supplementation where FEV1, FEV1/ FVC increased by $(17 \%, 13.6 \%)$ and $(15 \%, 8.7 \%)$. While FVC increased by $(11 \%$, $14 \%$ ) in CF and non-CF patients respectively (P-value < 0.001) (data not shown in the results).

These results were consistent with the findings of previous studies [3] [26] which have found an association between vitamin D deficiency and FEV1 in CF patients and reported that higher vitamin $\mathrm{D}$ status in children and adults with $\mathrm{CF}$ has been associated with better lung function assessed by (FEV1). In addition, Simoneau et al. [24] reported in his study that "there was a trend towards a greater increase in FEV1 in pediatric CF patients receiving vitamin D3 than those receiving vitamin D2 (2.4\% versus $0.7 \%)$ ".

Similarly, several studies [10] [27] found that higher 25(OH)D concentrations correlate with improved lung function in non-CF bronchiectasis. Furthermore, "a recently conducted study [28] in adult CF patients reported that a bolus of vitamin D instantly increased its concentration in serum, and significantly improved lung functioning".

To our knowledge, Our study is the first study to prove the improvement in parameters of lung functions and not only FEV1 after vitamin D3 supplementation in both $\mathrm{CF}$ and non-CF pediatric bronchiectasis patients.

These findings are consistent with the results of the Third National Health and Nutrition Examination Survey (NHANES III), where "there was a positive correlation between vitamin $\mathrm{D}$ status and lung function as assessed by (FEV1) and (FVC) [29] and patients with the highest vitamin D concentration had 126 $\mathrm{ml}$ higher (FEV1) and $173 \mathrm{ml}$ higher (FVC), in comparison with patients with significant hypovitaminosis $\mathrm{D}$. The protective effect of vitamin $\mathrm{D}$ in the course of chronic lung disease is mainly discerned in its anti-inflammatory and immune modulatory properties [9]".

Thus, the current study supports the hypothesis that bronchiectasis severity is associated with low 25-hydroxyvitamin D (25(OH)D) levels [10] and that Vitamin D therapy may enhance anti-microbial peptide production, decrease pro-inflammatory cytokines and decrease colonization of airway pathogens which precipitate the pulmonary exacerbations [9] which could result in improved clinical outcomes [11].

Depending on our results, vitamin D3 supplementation could be a reasonable cost-effective therapeutic approach for all patients with bronchiectasis. Addi- 
tionally, more concerted efforts should be undertaken to ensure that vitamin D status is optimized in all patients with CF and non-CF bronchiectasis.

\section{Study Limitations}

This study has some limitations, first, the adherence data may be limited as it was self reported by the studied patients. Second, the number of the studied patients may be small to generalize the results on all bronchiectasis patients.

\section{Conclusion}

We demonstrated the efficacy of therapeutic vitamin D3 in elevating the serum vitamin D level to the sufficient level in CF and non-CF bronchiectasis patients and concluded that elevated vitamin D level is associated with decreased frequency and severity of pulmonary exacerbations and improvement of lung function in both groups of patients especially non-CF bronchiectasis patients. Therefore, decreasing the disease severity. However, further future studies are still needed to document the use of vitamin D3 as a therapeutic tool and determine the most effective dose (not only in CF but also in non-CF bronchiectasis patients.

\section{Acknowledgements}

The authors deeply appreciated the help from our patients to finish this work.

\section{Funding Source}

No external funding was used for this manuscript.

\section{Conflict of Interest}

The authors have did not have any conflicts of interest to disclose.

\section{References}

[1] Murray, M.P. and Hill, A.T. (2009) Non-Cystic Fibrosis Bronchiectasis. Clinical Medicine, 9, 164-169. https://doi.org/10.7861/clinmedicine.9-2-164

[2] Brower, K.S., Del Vecchio, M.T. and Aronoff, S.C. (2014) The Etiologies of Non-CF Bronchiectasis in Childhood: A Systematic Review of 989 Subjects. BMC Pediatrics, 14, Article No. 299. https://doi.org/10.1186/s12887-014-0299-y

[3] Mccauley, L.A., Thomas, W., Laguna, T.A., Regelmann, W.E., Moran, A. and Polgreen, L.E. (2014) Vitamin D Deficiency Is Associated with Pulmonary Exacerbations in Children with Cystic Fibrosis. Annals of the American Thoracic Society, 2 198-204. https://doi.org/10.1513/AnnalsATS.201208-068OC

[4] Janssens, W., Bouillion, R., Claes, B., et al. (2010) Vitamin-D Deficiency Is Highly Prevalent in COPD and Correlates with Variants in the Vitamin-D-Binding Gene. Thorax, 65, 215-220. https://doi.org/10.1136/thx.2009.120659

[5] Bartley, J., Garrett, J., Grant, C.C. and Camargo Jr., C.A. (2013) Could Vitamin D Have A Potential Anti-Inflammatory and Anti-Infective Role in Bronchiectasis? Current Infectious Disease Reports, 15, 148-157.

https://doi.org/10.1007/s11908-013-0321-9 
[6] Herscovitch, K., Dauletbaev, N. and Lands, L.C. (2014) Vitamin D as an Antimicrobial and Anti-Inflammatory Therapy for Cystic Fibrosis. Paediatric Respiratory Reviews, 15, 154-162. https://doi.org/10.1016/j.prrv.2013.11.002

[7] Herscovitch, K., Dauletbaev, N., Berube, J., Rousseau, S. and Lands, L. (2012) Supplementation with 25-Hydroxyvitamin D3 Down-Regulates Pathogen-Stimulated Interleukin-8 Production in Cystic Fibrosis Macrophages and Airway Epithelial Cells. American Journal of Respiratory and Critical Care Medicine, 185, A2803. https://doi.org/10.1164/ajrccm-conference.2012.185.1_MeetingAbstracts.A2803

[8] Majak, P., Jerzyńska, J., Smejda, K., Stelmach, I., Timler, D. and Stelmach, W. (2012) Correlation of Vitamin D with Foxp3 Induction and Steroid-Sparing Effect of Immunotherapy in Asthmatic Children. Annals of Allergy, Asthma \& Immunology, 109, 329-335. https://doi.org/10.1016/j.anai.2012.08.002

[9] Moustakim, L.J, Priftis, K. and Douros, K. (2017) Role of Vitamin D in Cystic Fibrosis and Non-Cystic Fibrosis Bronchiectasis. World Journal of Clinical Pediatrics, 3, 132-142. https://doi.org/10.5409/wjcp.v6.i3.132

[10] Chalmers, J.D., Mchugh, B.J., Docherty, C., Govan, J.R. and Hill, A.T. (2013) Vitamin-D Deficiency Is Associated with Chronic Bacterial Colonization and Disease Severity in Bronchiectasis. Thorax, 68, 39-47.

https://doi.org/10.1136/thoraxjnl-2012-202125

[11] Chesdachai, S. and Tangpricha, V. (2016) Treatment of Vitamin D Deficiency in Cystic Fibrosis. The Journal of Steroid Biochemistry and Molecular Biology, 164, 36-39. https://doi.org/10.1016/j.jsbmb.2015.09.013

[12] Colombo, C., Ellemunter, H., Houwen, R., Munck, A., Taylor, C. and Wilschanski, M. (2011) Guidelines for the Diagnosis and Management of Distal Intestinal Obstruction Syndrome in Cystic Fibrosis Patients. Journal of Cystic Fibrosis, 2, S24-S28. https://doi.org/10.1016/S1569-1993(11)60005-2

[13] Chang, A.B., Bell, S.C., Torzillo, P.J., King, P.T., Maguire, G.P., Byrnes, C.A., Holland, A.E., O’Mara, P., Grimwood, K. and Extended Voting Group (2015) Chronicsuppurative Lung Disease and Bronchiectasis in Children and Adults in Australia and New Zealand Thoracic Society of Australia and New Zealand Guidelines. Medical Journal of Australia, 202, 130. https://doi.org/10.5694/mjac14.00287

[14] Miller, M.R., Hankinson, J., Brusasco, V., Burgos, F., Casaburi, R., Coates, A., et al. (2005) Standardisation of Spirometry. European Respiratory Journal, 26, 319-338. https://doi.org/10.1183/09031936.05.00034805

[15] American Thoracic Society (1994) Standardization of Spirometry. American Journal of Respiratory and Critical Care Medicine, 152, 1107-1136.

[16] Fuchs, H.J., Borowitz, D.S., Christiansen, D.H., Morris, E.M., Nash, M.L., Ramsey, B.W., Rosenstien, B.J., Smith, A.L. and Wohl, M. (1994) Effect of Aerosolized Recombinant Human Dnase on Exacerbations of Respiratory Symptoms and on Pulmonary Function in Patients with Cystic Fibrosis. New England Journal of Medicine, 10, 637-642. https://doi.org/10.1056/NEJM199409083311003

[17] Pasteur, M.C., Bilton, D. and Hill, A.T. (2010) British Thoracic Society Guideline for Non-CF Bronchiectasis. Thorax, 65, i1-i58.

https://doi.org/10.1136/thx.2010.136119

[18] Borowitz, D., Robinson, K., Rosenfeld, M., Davis, S.D., Sabadosa, K.A., Spear, S.L., Michel, S.H., Parad, R.B., White, T.B., Farell, P.M., Marshall, B.C. and Accurso, F.J. (2009) Cystic Fibrosis Foundation Evidence-Based Guidelines for Management of Infants with Cystic Fibrosis. The Journal of Pediatrics, 155, S73-S93. 
https://doi.org/10.1016/j.jpeds.2009.09.001

[19] Chalmers, J.D., Aliberti, S., Filonenko, A., et al. (2018) Characterization of the "Frequent Exacerbator Phenotype" in Bronchiectasis. American Journal of Respiratory and Critical Care Medicine, 197, 1410-1420. https://doi.org/10.1164/rccm.201711-2202OC

[20] Tangpricha, V., Kelly, A., Stephenson, A., Maguiness, K., Enders, J., Robinson, K.A., et al. (2012) An Update on the Screening, Diagnosis, Management, and Treatment of Vitamin D Deficiency in Individuals with Cystic Fibrosis: Evidence-Based Recommendations From the Cystic Fibrosis Foundation. The Journal of Clinical Endocrinology Metabolism, 4, 1082-1093. https://doi.org/10.1210/jc.2011-3050

[21] Holick, M.F. (2009) Vitamin D Status: Measurement, Interpretation and Clinical Application. Annals of Epidemiology, 2, 73-78.

https://doi.org/10.1016/j.annepidem.2007.12.001

[22] Holick, M.F., Binkley, N.C., Bischoff-Ferrari, H.A., Gordon, C.M., Hanley, D.A., Heaney, R.P., Murad, M.H. and Weaver, C.M. (2011) Endocrine Society. Evaluation, Treatment, and Prevention of Vitamin D Deficiency: An Endocrine Society Clinical Practice Guideline. The Journal of Clinical Endocrinology \& Metabolism, 7, 1911-1930. https://doi.org/10.1210/jc.2011-0385

[23] Bartley, J., Garrett, J., Camargo, C., Scragg, R., Vandal, A., Sisk, R., et al. (2018) Vitamin D3 Supplementation in Adults with Bronchiectasis: A Pilot Study. Chronic Respiratory Disease, 15, 384-392. https://doi.org/10.1177/1479972318761646

[24] Simoneau, T., Sawicki, G., Carly, E., Milliren, E., Feldman, H. and Gordon, C. (2016) Randomized Controlled Trial of Vitamin D Replacement Strategies in Pediatric CF Patients. Journal of Cystic Fibrosis, 15, 234-241. https://doi.org/10.1016/j.jcf.2015.07.004

[25] Grossmann, R.E., Zughaier, S.M., Kumari, M., Seydafkan, S., Lyles, R.H., Liu, S.L., Sueblinvong, V., Schechter, M.S., Stecenkoa, A., Ziegler, T.R. and Tangpricha, V. (2012) Pilot Study of Vitamin D Supplementation in Adults with Cystic Fibrosis Pulmonary Exacerbation: A Randomized, Controlled Trial. Dermato-Endocrinology, 4, 191-197. https://doi.org/10.4161/derm.20332

[26] Green, D., Carson, K., Leonard, A., Davis, J.E., Rosenstein, B., Zeitlin, P. and Mogayzel Jr., P. (2008) Current Treatment Recommendations for Correcting Vitamin D Deficiency in Pediatric Patients with Cystic Fibrosis Are Inadequate. The Journal of Pediatrics, 153, 554-559. https://doi.org/10.1016/j.jpeds.2008.04.058

[27] Konstan, M.W., Wagener, J.S., Vandevanter, D.R., Pasta, D.J., Yegin, A., Rasouliyan, L. and Morgan, W.J. (2012) Risk Factors for Rate of Decline in FEV1 in Adults with Cystic Fibrosis. Journal of Cystic Fibrosis, 11, 405-411. https://doi.org/10.1016/j.jcf.2012.03.009

[28] Tangpricha, V., Smith, E.M., Binongo, J., et al. (2017) The Vitamin D for Enhancing the Immune System in Cystic Fibrosis (DISC) Trial: Rationale and Design of A Multi-Center, Double-Blind, Placebocontrolled Trial of High Dose Bolus Administration of Vitamin D3 During Acute Pulmonary Exacerbation of Cystic Fibrosis. Contemporary Clinical Trials Communications, 6, 39-45. https://doi.org/10.1016/j.conctc.2017.02.010

[29] Black, P.N. and Scraggr, R. (2005) Relationship between Serum 25-Hydroxyvitamin $\mathrm{D}$ and Pulmonary Function in the Third National Health and Nutrition Examination Survey. Chest, 128, 3792-3798. https://doi.org/10.1378/chest.128.6.3792 